\title{
Residual Stress Analysis of Cylindrical Solid Oxide Fuel Cells
}

\author{
Tohru KATO, Akihiko MOMMA, Susumu NAGATA and Yasuhiro KASUGA \\ Energy Fundamentals Division, Electrotechnical Laboratory, AIST, 1-1-4, Umezono, Tsukuba-shi, Ibaraki 305
}

\author{
円筒型固体電解質燃料電池の残留応力解析 \\ 嘉藤 徹・門馬昭彦・永田 進・春日康弘 \\ 電子技術総合研究所エネルギー基礎部，305 茨城県つくば市梅園 1-1-4
}

\begin{abstract}
The dependence of the residual stress in cylindrical solid oxide fuel cells ( $\mathrm{SOFCs)} \mathrm{on} \mathrm{the} \mathrm{structures} \mathrm{and} \mathrm{the}$ process temperatures was estimated using the analytical modeling of an axisymmetric structure. From the results of the analysis the following points were discovered. In the case of a 4 -layered structure, which is supported by a porous insulation tube of calcia-stabilized zirconia ( $C S Z$ ), the circumferential and axial stresses induced in the electrodes are so high that they can break the structure under the assumed realistic conditions. A method for reducing these stresses is discussed. On the other hand, in the case of a 3-layered structure which is supported by an inner electrode tube, tensile stresses in the electrodes can be reduced to several MPa if the total thickness of two electrodes is more than 60 times the thickness of the electrolyte. New material for the substrate tube is proposed on the basis of the obtained results.
\end{abstract}

[Received January 24, 1997; Accepted August 7, 1997]

Key-words : Solid oxide fuel cell, Residual stress, Coaxial multilayer structure, Degradation, Analytical model

\section{Introduction}

The Solid oxide fuel cell (SOFC) is an all solid state fuel cell which is operated at approximately $1000^{\circ} \mathrm{C}$. The cell consists of a dense oxide ion conducting electrolyte and two porous electrodes. Yttria-stabilized zirconia (YSZ) is most commonly used as the electrolyte in SOFCs. Ni-YSZ cermet and perovskite oxide like $\mathrm{La}_{1-x} \mathrm{Sr}_{x} \mathrm{MnO}_{3}$ are often selected as the anode and cathode, respectively, due to their electronic conductivity, catalytic performance and chemical stability. ${ }^{1)}$ In addition to the general advantages of fuel cells, ${ }^{2)}$ like high energy conversion efficiency and low air pollutant emission rates, the SOFCs have other advantages, ${ }^{1), 3)}$ such as the simple system concept without an external reformer, generation of high quality heat and high CO-resistance because of high temperature operations.

The degradation of the performance of SOFCs is frequently observed during long term operations. There may be several factors that can cause this degradation: thermal stress, ${ }^{4), 5)}$ decrease of mechanical strength of the component material with the thermal cycle and the operation time, the sintering behavior of porous electrodes ${ }^{6)}$ and chemical reactions among component materials under operating condition. ${ }^{7-12)}$ So far, several investigations have been carried out on chemical degradation. However, information regarding other factors has been extremely limited.

As all components of SOFC are solid, during the fabrication of SOFC or at the beginning of the operation, the thermal stress, which was caused by temperature distribution and the mismatches of coefficient of thermal expansion (CTE) between the component materials, can become a serious problem resulting in the degradation of SOFC. From this point of view, Kanamura et al. estimated the thermal stress under the operating conditions.4),5) In general, however, SOFC is fabricated at temperatures higher than $1000^{\circ} \mathrm{C}$ by some manufacturing processes such as sintering or $\mathrm{CVD} / \mathrm{EVD}^{13)-15)}$ and their operation temperature is approximately $1000^{\circ} \mathrm{C}$. Hence, considering the thermal stress problem, the residual stress at room temperature can be fatal for the SOFC structure. Therefore, in this paper, dependence of the residual stress on material properties and dimensions of cell components is studied and a method for prevention is discussed for the cylindrical SOFCs. Cylin- drical SOFCs can be divided into two types depending on the cell structure. One is a 4-layered structure composed of a CSZ substrate tube having a similar value for the CTE as the XSZ electrolyte, the other structure is a 3-layered structure supported by an electrode tube. The analysis is performed for both types.

\section{Calculation of residual stress}

For this analysis, the cell was treated as a long coaxial multilayer tube (Fig. 1) under uniform temperature conditions without any external force. It was assumed that each layer was isotropic and elastic. The components of stress on each layer satisfy the equations of equilibrium as follows. ${ }^{16)}$

$$
\begin{aligned}
& \frac{\partial \sigma_{r r}}{\partial r}+\frac{\partial \sigma_{z r}}{\partial z}+\frac{\sigma_{r r}-\sigma_{\theta 0}}{r}=0 \\
& \frac{\partial \sigma_{z r}}{\partial r}+\frac{\partial \sigma_{z z}}{\partial z}+\frac{\sigma_{z r}}{r}=0
\end{aligned}
$$

The stress-displacement relationships are expressed with cylindrical coordinates as follows.

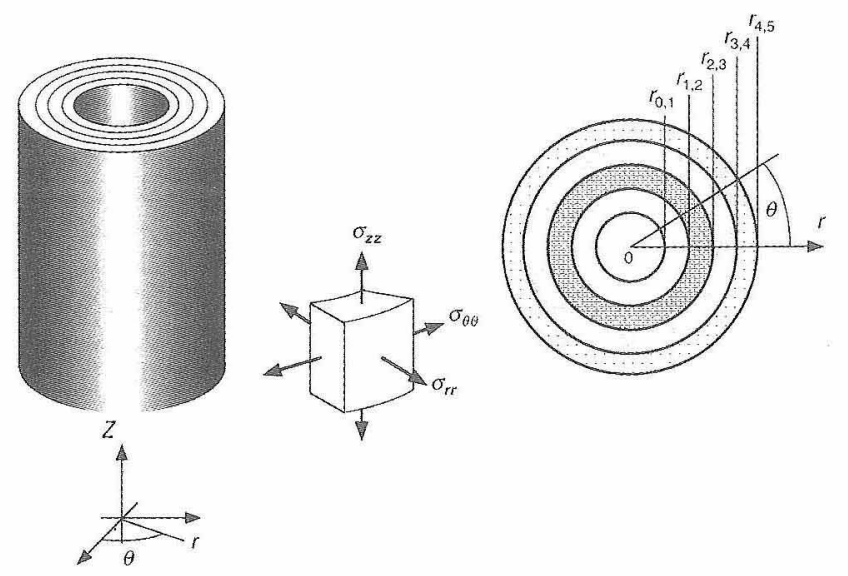

Fig. 1. The model of cylindrical SOFC. 


$$
\begin{aligned}
\sigma_{r r}= & \frac{E}{1-v}\left\{\frac{1-v}{1-2 v} \frac{\partial u_{r}}{\partial r}-\frac{v}{1-2 v}\left(\frac{u_{r}}{r}+\frac{\partial u_{z}}{\partial z}\right)\right\} \\
& -\frac{\alpha E}{1-v} \Delta T \\
\sigma_{\theta \theta}= & \frac{E}{1-v}\left\{\frac{1-v}{1-2 v} \frac{u_{r}}{r}-\frac{v}{1-2 v}\left(\frac{\partial u_{r}}{\partial r}+\frac{\partial u_{z}}{\partial z}\right)\right\} \\
& -\frac{\alpha E}{1-v} \Delta T \\
\sigma_{z z}= & \frac{E}{1-v}\left\{\frac{1-v}{1-2 v} \frac{\partial u_{z}}{\partial z}-\frac{v}{1-2 v}\left(\frac{\partial u_{r}}{\partial r}+\frac{u_{r}}{r}\right)\right\} \\
& -\frac{\alpha E}{1-v} \Delta T \\
\sigma_{r z}= & \frac{E}{2(1-v)}\left(\frac{\partial u_{r}}{\partial z}+\frac{\partial u_{z}}{\partial r}\right)
\end{aligned}
$$

Where, $\sigma, u, E, \alpha$ and $v$ denote stress tensor, displacement vector, Young's modulus, CTE and Poisson' ratio, respectively. $\Delta T$ denotes the temperature difference of each layer between the assumed temperature for calculating stress and the fabrication temperature. The shear stresses $\sigma_{\theta z}$ and $\sigma_{\theta r}$ are zero because of their symmetry about the $z$-axis. Assuming that the tube is long enough, it is considered that all layers can elongate or shrink uniformly along the $z$-axis as the temperature changes. Therefore, axial shear stress $\sigma_{r z}$ is supposed to be approximately zero.

It was assumed that each layer would be fabricated in order starting from the inside on the substrate tube at the fabrication temperature $T_{i}$ and the thickness $d_{i}$ (the subscript $i$ denotes order of layer from the inside) and its thermal stress would be zero when it is deposited. The following boundary conditions were adopted.

(1) Radial stresses $\sigma_{r r}$ at the inner and the outer surface are zero.

(2) $\sigma_{r r}$ is balanced and radial displacement $u_{r}$ is continuous at the interface between layers.

(3) Integration of axial stress $\sigma_{z z}$ on the parallel $r-\theta$ plane cross section is zero.

The equations of boundary conditions for each layer are as follows. According to continuity of displacement,

$$
\begin{array}{ll}
u_{r, i, 1}\left(r_{1,2}, T\right)=u_{r, i, 2}\left(r_{1,2}, T\right) & (i \geq 2) \\
u_{z, i, 1}\left(r_{1,2}, T\right)=u_{z, i, 2}\left(r_{1,2}, T\right) & (i \geq 2)
\end{array}
$$

When $i$-th layer $(i \geqq 3)$ is fabricated, the displacement of $i$ th layer is zero, while the displacement of $(i-1)$-th layer arises from a temperature difference between $T_{i}$ and $T_{i-1}$. This displacement is equivalent to the displacement of $(i-1)$-th layer in $(i-1)$-layered structure at temperature $T_{i}$ because of the assumption mentioned above.

$$
\begin{aligned}
& u_{r, i, i}\left(r_{i-1, i}, T\right) \\
& \quad=u_{r, i, i-1}\left(r_{i-1, i}, T\right)-u_{r, i, i-1}\left(r_{i-1, i}, T_{i}\right) \\
& \quad=u_{r, i, i-1}\left(r_{i-1, i}, T\right)-u_{r, i-1, i-1}\left(r_{i-1, i}, T_{i}\right) \\
& \begin{aligned}
u_{z, i, i}\left(r_{i-1, i}, T\right) & (i \geq 3) \\
\quad & u_{z, i, i-1}\left(r_{i-1, i}, T\right)-u_{z, i, i-1}\left(r_{i-1, i}, T_{i}\right) \\
& =u_{z, i, i-1}\left(r_{i-1, i}, T\right)-u_{z, i-1, i-1}\left(r_{i-1, i}, T_{i}\right)
\end{aligned}
\end{aligned}
$$

According to the boundary conditions for $\sigma_{r r}$

$$
\begin{aligned}
& \sigma_{r r, i, 1}\left(r_{0,1}, T\right)=0 \quad(i \geq 2) \\
& \sigma_{r r, i, i}\left(r_{i, i+1}, T\right)=0 \quad(i \geq 2) \\
& \sigma_{r r, i, k}\left(r_{k, k+1}, T\right)=\sigma_{r r, i, k+1}\left(r_{k, k+1}, T\right)
\end{aligned}
$$

$$
(i \geq 2, i-1 \geq k) \text {. }
$$

Considering that stresses in the direction of $z$-axis are balanced and $\sigma_{r z}$ is zero,
Table 1. Material Properties of the Components of SOFC

\begin{tabular}{cccccc}
\hline $\begin{array}{c}\text { Component } \\
\text { material }\end{array}$ & $\begin{array}{c}\text { Young's } \\
\text { modulus } \\
E_{0} / \mathrm{GPa}\end{array}$ & $\begin{array}{c}\text { Poisson's } \\
\text { ratio } v\end{array}$ & $\begin{array}{c}\mathrm{CTE} \\
10^{6} \alpha / 1 /{ }^{\circ} \mathrm{C}\end{array}$ & $\begin{array}{c}\text { Porosity } \\
P / \%\end{array}$ & $\begin{array}{c}\text { Young's } \\
\text { modulus } \\
\text { of porous } \\
\text { material } \\
E / \mathrm{GPa}\end{array}$ \\
\hline $\begin{array}{c}\mathrm{CSZ} \\
\begin{array}{l}\mathrm{Ni}-\mathrm{YSZ} \\
(\mathrm{Ni}: \mathrm{YSZ}=\end{array}\end{array}$ & 208 & 0.3 & 9.1 & 32.6 & 99 \\
$40: 60$ mass $\%)$ & 207 & 0.3 & 12.1 & 30 & 106 \\
$\quad \mathrm{YSZ}$ & 208 & 0.3 & 10.3 & 0 & - \\
$\mathrm{La}_{0.89} \mathrm{Sr}_{0.1} \mathrm{MnO}_{3}$ & 154 & 0.3 & 12 & 30 & 79 \\
\hline
\end{tabular}

$$
\sum_{k=1}^{i} \int_{r_{k-1, k}}^{r_{k, k+1}} \sigma_{z z, i, k}(r, T) r \mathrm{~d} r=0
$$

In these equations, $u_{r, i, j}$ represents $u_{r}$ in $j$-th layer when $i$-th layer has been fabricated. $u_{z, i, j}, \sigma_{r r, i, j}$ and $\sigma_{z z, i, j}$ have similar meaning. $r_{i-1, i}$ denotes the location of interface between $(i-1)$-th layer and $i$-th layer. In particular, $r_{i, i+1}$ in $i$-layered structure and $r_{0,1}$ denote the locations of the outer surface and the inner surface.

The properties of SOFC component materials are listed in Table 1. These were used to decide the parameter ranges for calculation. Young's moduli for the porous materials were estimated using the following empirical equation. ${ }^{17)}$

$$
E=E_{0}\left(1-1.9 P+0.9 P^{2}\right)
$$

$E_{0}$ and $P$ denote Young's modulus of the dense material and porosity of porous material, respectively. CTE of Ni-YSZ cermet $\alpha_{\text {cer }}$ was estimated using Turner's model. ${ }^{18)}$

$$
\alpha_{\mathrm{cer}}=\frac{\sum_{i} \alpha_{i} K_{i} F_{i} / \rho_{i}}{\sum_{i} K_{i} F_{i} / \rho_{i}}
$$

Where $K_{i}, F_{i}$ and $\rho_{i}$ denote bulk modulus, weight fraction and density of component $i$, respectively.

For the actual fabrication of SOFC, the material properties and the thickness of the YSZ electrolyte should be selected in a very narrow range so as not to decrease cell performance. On the contrary, for the electrodes, the material properties and the thicknesses can be widely changed by controlling composition and porosity of the materials. Therefore, in the calculation, parameters on the properties of electrodes were widely changed. The inner diameter of the cell was fixed at $12.7 \mathrm{~mm}$ and the thickness of the electrolyte was $0.05 \mathrm{~mm}$. The material properties of YSZ are shown in Table 1.

\section{Results and discussion}

\subsection{4-layered structure}

Figure 2 shows the residual stress distributions obtained for the 4-layered structure by employing the data given in Table $1 . \sigma_{r r}$ is a small compressive stress over all regions. However, $\sigma_{z z}$ and $\sigma_{\theta \theta}$ induced in the two electrodes are large tensile stresses. Particularly, those in the inner electrode are more than $200 \mathrm{MPa}$ under the given conditions. These stresses are too large and result in the fracturing of the porous electrodes. The influence of material properties on stress distribution in the inner electrode is shown in Fig. 3. For simplifying the calculation, it was assumed that material properties of both electrodes were equivalent and CTE of substrate was equal to that of YSZ. The stress decreases with decreasing $E\left(\alpha-\alpha_{3}\right)$. To reduce the stress to $\mathrm{MPa}$ level, the difference between CTE of component 

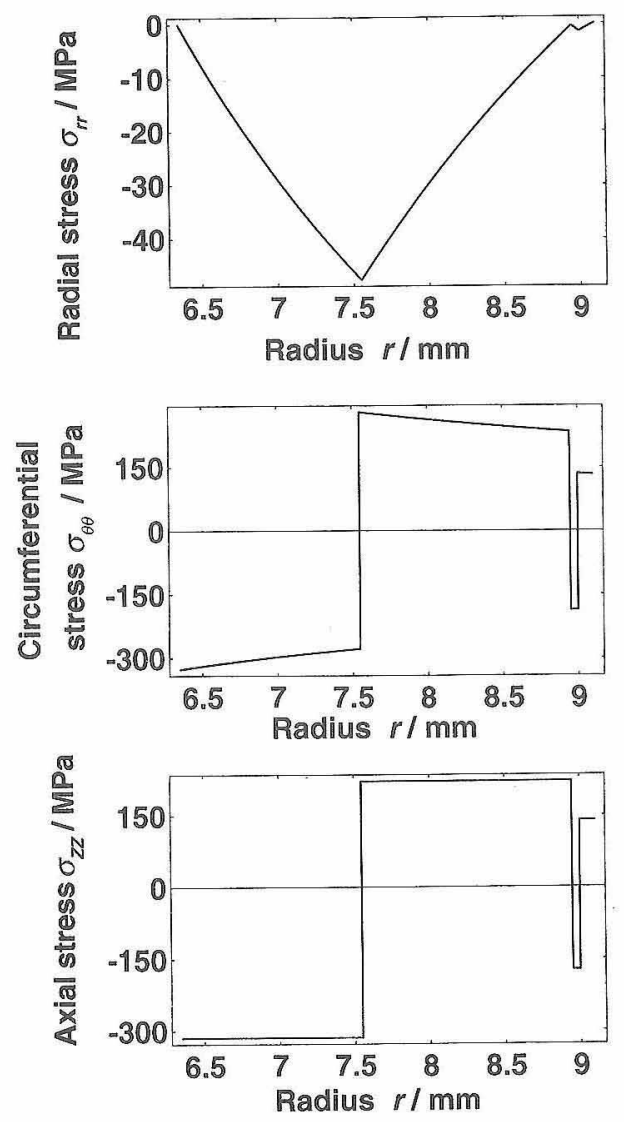

Fig. 2. Residual stress distribution for the 4-layered structure. $\mathrm{Ni}-\mathrm{YSZ}$ was assumed as the inner electrode. $T_{2}=1300^{\circ} \mathrm{C}, T_{3}=T_{4}$ $=1100^{\circ} \mathrm{C}, d_{1}=1.2 \mathrm{~mm}, d_{2}=1.4 \mathrm{~mm}, d_{4}=0.1 \mathrm{~mm}$.

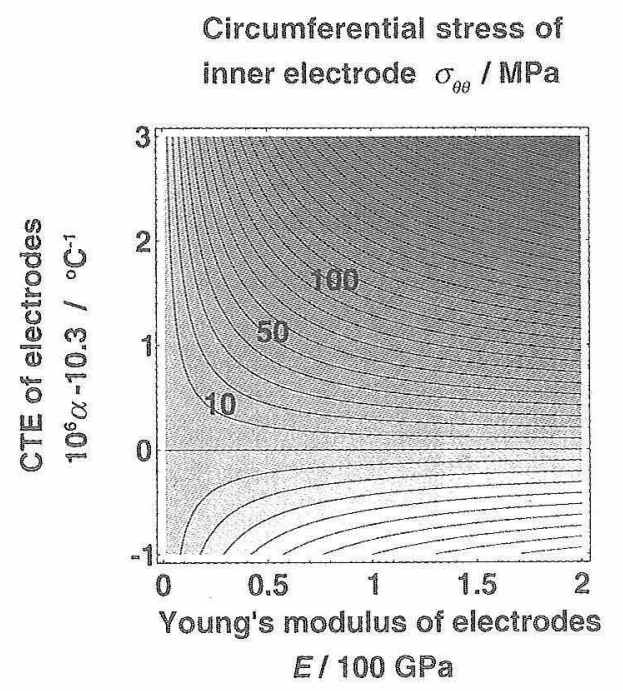

Fig. 3. Dependence of the circumferential stress $\sigma_{\theta \theta}$ in the inner electrode on the material constants of electrodes. The gradation from white to black corresponds with the increase of $\sigma_{\theta \theta}$ and one line was drawn every $10 \mathrm{MPa} . T_{2}=T_{3}=T_{4}=1100^{\circ} \mathrm{C}, \alpha=\alpha_{2}=\alpha_{4}, \alpha_{1}$ $=\alpha_{3}=10.3 \times 10^{-6}{ }^{\circ} \mathrm{C}^{-1}, E=E_{2}=E_{4}, E_{1}=99 \mathrm{GPa}, E_{3}=208 \mathrm{GPa}, d_{1}$ $=1.2 \mathrm{~mm}, d_{2}=1.4 \mathrm{~mm}, d_{4}=0.1 \mathrm{~mm}$.

materials must be within the order of $10^{-7}{ }^{\circ} \mathrm{C}^{-1}$ or Young's moduli of porous materials must be very small. Because a reduction of the difference between CTE of component materials could deteriorate the electrical performance of electrodes and the decrease in Young's moduli could lower

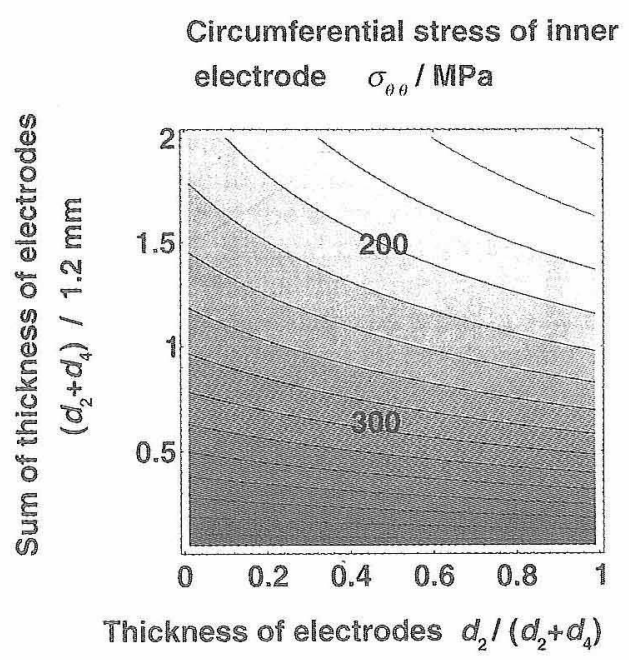

Fig. 4. Dependence of the circumferential stress $\sigma_{\theta \theta}$ in the inner electrode on the thickness of electrodes. The gradation from white to black corresponds with the increase of $\sigma_{\theta \theta}$ and one line was drawn every $20 \mathrm{MPa}$. $T_{2}=T_{3}=T_{4}=1100^{\circ} \mathrm{C}$.

the strength of porous materials, these concepts must be applied carefully. Figure 4 shows the dependence of the stress distribution in the inner electrode on the electrode thickness. The tensile stress decreases with increasing the total thickness of electrodes, but, the decreasing rate is not large, because the substrate thickness is thicker than the total thickness of electrodes. Even if the total thickness of electrodes is equal to that of the substrate, the magnitude of stress in the inner electrode is more than $240 \mathrm{MPa}$. Therefore, this is not a promising method.

Figure 5 shows the stress dependence on the fabrication temperatures of electrodes. $\sigma_{z z}$ and $\sigma_{\theta \theta}$ of the electrodes at room temperature decrease with reducing electrode fabrication temperatures. In order to reduce $\sigma_{z z}$ and $\sigma_{00}$ to $\mathrm{MPa}$ level, two electrodes must be fabricated at the temperature lower than $100^{\circ} \mathrm{C}$. In this case, the tensile stress in every layer at the operating temperature can be decreased to the magnitude of several $\mathrm{MPa}$ too. However, $\sigma_{r r}$ at the operating temperature is tensile in all regions and shows the maximum value at the interface between the substrate and the inner electrode. Then, if bonding strength in some interfaces is lower than $\sigma_{r r}$, the delamination will occur at the interface. Furthermore, it can be consider that the stress distribution profile is changed during the long term operation by the annealing effect and $\sigma_{z z}$ and $\sigma_{\theta \theta}$ at room temperature increase to a harmful value. For SOFC fabricated by the plasma spraying method, degradation is sometimes observed during the cooling after the operation. The details of this phenomenon have not yet been determined. The statements given above can hypothetically explain the degradation if the temperatures of the porous electrode fabricated by plasma spraying are much lower than the operating temperature.

3.2 3-layered structure

Figure 6 shows the residual stress distribution in the 3layered structure. In contrast to the 4 -layered structure, $\sigma_{z z}$ and $\sigma_{\theta \theta}$ in the two electrodes are in the magnitude of several MPa because the total thickness of the electrodes $d_{1}+d_{3}$ is much larger than the thickness of electrolyte $d_{2}$. The dependence of $\sigma_{\theta \theta}$ in the inner electrode on both electrodes thicknesses is shown in Fig. 7. If $d_{1}+d_{3}$ are approximately 60 times thicker than $d_{2}, \sigma_{z z}$ and $\sigma_{\theta \theta}$ become less than 10 $\mathrm{MPa}$. This gives a practical condition for cylindrical SOFCs. On the one hand, $\sigma_{z z}$ and $\sigma_{\theta \theta}$ in the electrolyte show compressive stresses more than $600 \mathrm{MPa}$. But the com- 
(a)
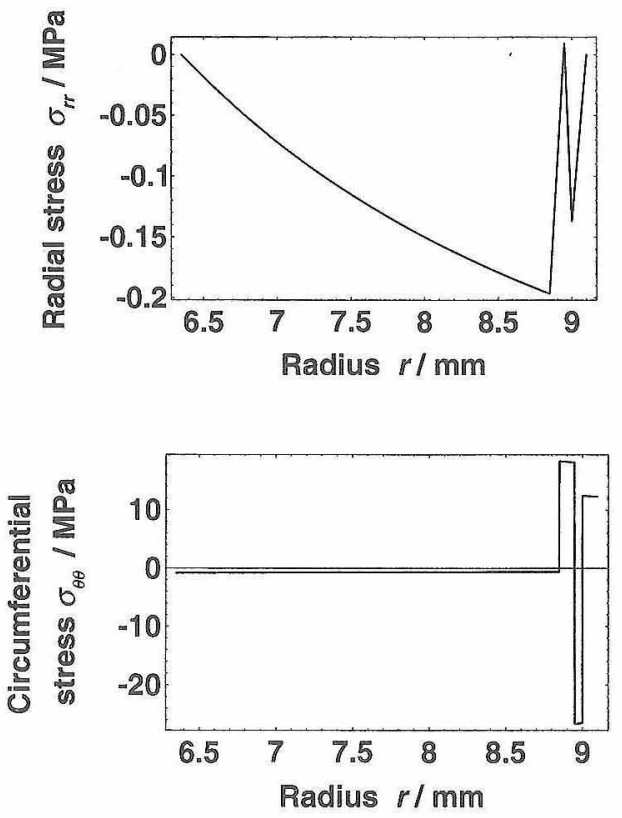

(b)
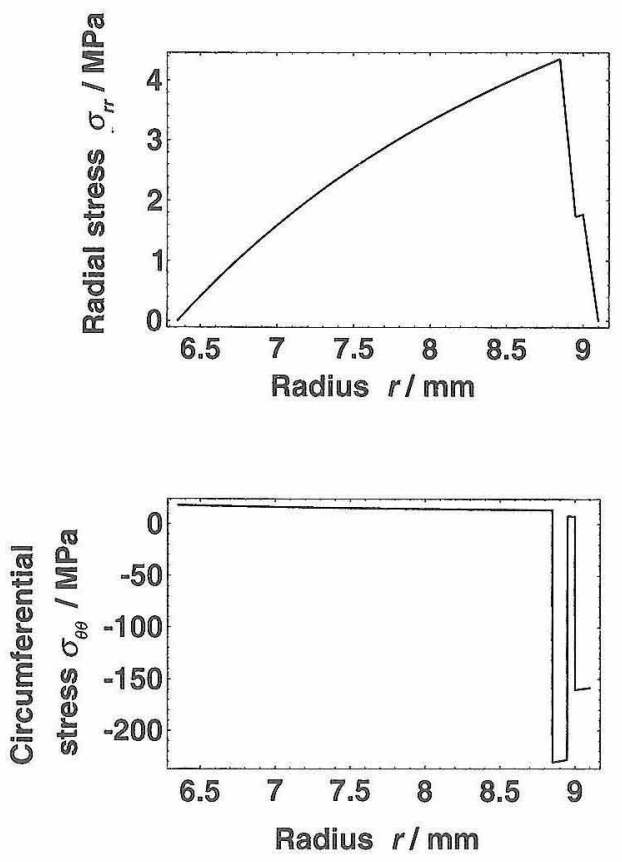

Fig. 5. The stress distribution of the 4-layered structure with the two electrodes deposited at low temperature. (a) Room temperature $\left(30^{\circ} \mathrm{C}\right),(\mathrm{b})$ Operating temperature $\left(1000^{\circ} \mathrm{C}\right) \cdot T_{2}=T_{4}$ $=110^{\circ} \mathrm{C}, T_{3}=1100^{\circ} \mathrm{C}, d_{2}=d_{4}=0.1 \mathrm{~mm}, d_{1}=2 \mathrm{~mm}, d_{3}=0.05 \mathrm{~mm}, \alpha_{1}$ $=10.3 \times 10^{-6}{ }^{\circ} \mathrm{C}^{-1}$.

pressive strength of YSZ is more than several $\mathrm{GPa}$, which is large enough in comparison with $\sigma_{z z}$ and $\sigma_{\theta \theta}$. On the other hand, $\sigma_{r r}$ is tensile in all regions and shows the maximum value at the interface between the inner electrode and the electrolyte, as in the case shown in Fig. 5. The dependence of $\sigma_{r r}$ at the point on $d_{1}$ and $d_{3}$ is shown in Fig. 8. For the parameters in the lower right area, which are actual values for the cylindrical SOFC, $\sigma_{r r}$ is approximately $3 \mathrm{MPa}$ and almost independent of $d_{1}$ and $d_{3}$. Figure 9 shows the dependence of $\sigma_{r r}$ on $T_{3} . \sigma_{r r}$ slightly decreases with increasing $T_{3}$. Hence, if the delamination occurs at any interface, the bonding strength is required to overcome it.

Figure 10 shows the influence of the difference in CTE between the inner and the outer electrodes on the stress in
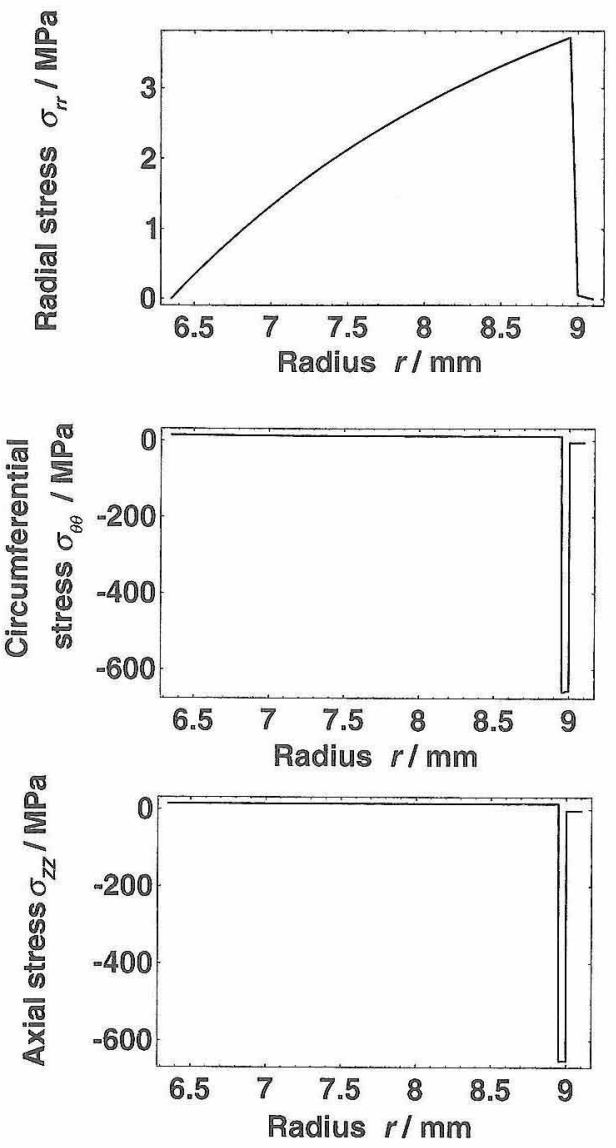

Fig. 6. Residual stress distribution for the 3-layered structure. $T_{2}$ $=T_{3}=1300{ }^{\circ} \mathrm{C}, d_{1}=2.6 \mathrm{~mm}, d_{3}=0.1 \mathrm{~mm}$.

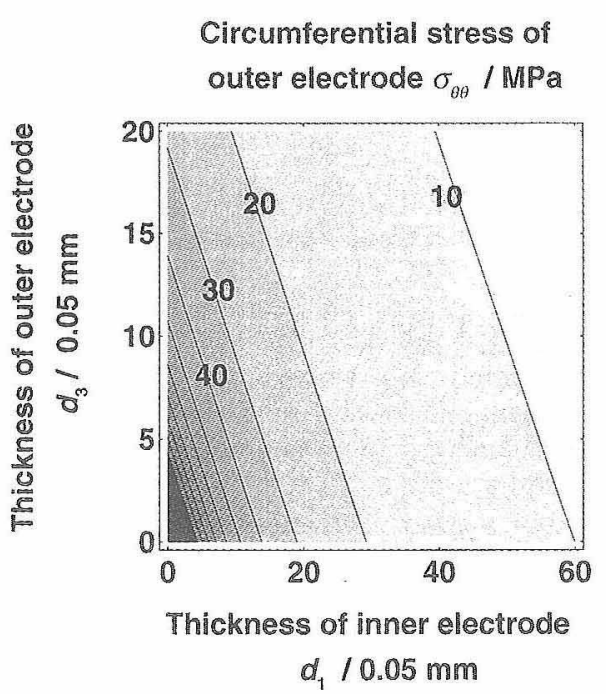

Fig. 7. Dependence of the circumferential stress $\sigma_{\theta \theta}$ in the outer electrode on the thickness of electrodes. The gradation from white to black corresponds with the increase of $\sigma_{\theta \theta}$ and one line was drawn every $10 \mathrm{MPa}$.

the outer electrode. If the CTE of the thick inner electrode is slightly smaller than that of the outer electrode, higher tensile stress is induced in the outer electrode. So, the electrode in which CTE is larger than that of another electrode should be employed as the support tube.

As mentioned above, it is clear that the 3-layered struc- 
Radial stress at inner electrodeelectrolyte interface $\sigma_{r r} / \mathrm{MPa}$

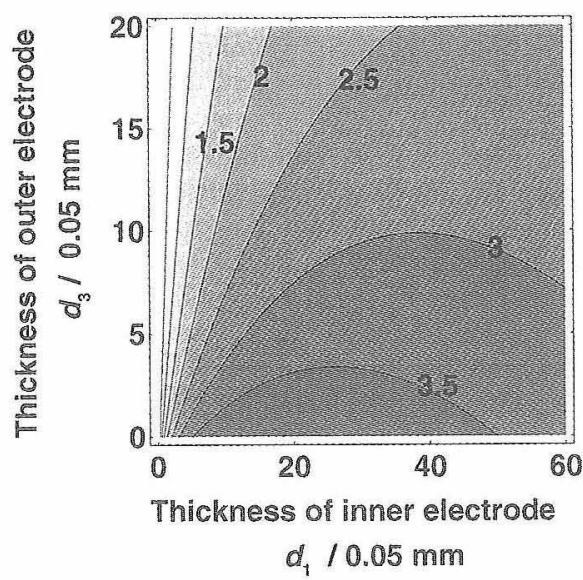

Fig. 8. Dependence of the radial stress $\sigma_{r r}$ at the interface between the inner electrode and the electrolyte on the thickness of electrodes. The gradation from white to black corresponds with the increase of $\sigma_{r}$ and one line was drawn every $0.5 \mathrm{MPa}$.

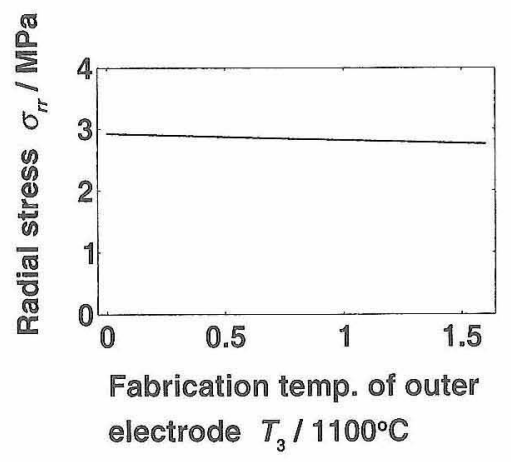

Fig. 9. Dependence of the radial stress $\sigma_{r r}$ at the interface between the inner electrode and the electrolyte on $T_{3} . T_{2}=1100^{\circ} \mathrm{C}$.

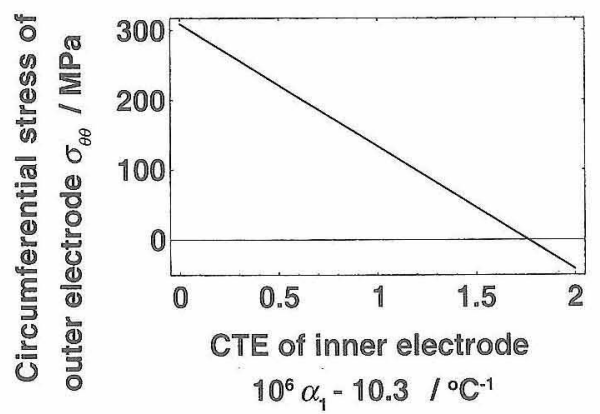

Fig. 10. Dependence of the circumferential stress $\sigma_{\theta \theta}$ in the outer electrode on CTE of the inner electrode $\alpha_{1} . T_{2}=T_{3}=1300^{\circ} \mathrm{C}, d_{1}$ $=2.6 \mathrm{~mm}, d_{3}=0.1 \mathrm{~mm}$.

ture is superior to the 4-layered type only if each interface has a strength high enough to resist radial tensile stresses. But this type has a few demerits with respect to the limitation in the configuration of interconnection and the expense of the substrate electrode tube. Practically, the long and narrow interconnection along the z-axis which has been adopted by Westinghouse Electric Corporation is only a reasonable form for this type. ${ }^{19)}$ As to the cost, both electrode materials are more expensive than CSZ. Because the thickness of the support tube is much thicker than that of the cell itself, applying the electrode to the support tube results in an increase in the cost of the cell.

If the support tube of the 4-layered cell is made from the insulator whose CTE is equal to that of the inner electrode material, then this cell has the same merits of mechanical properties as those of the 3-layered type. In addition, applying such a support tube to the cell construction will permit flexibility in selecting interconnection configurations.

A mixture of $\mathrm{MgAl}_{2} \mathrm{O}_{4}$ and $\mathrm{MgO}$, which is a good insulator under the operating conditions, is one of the promising materials for the support tube, because its CTE is controlled to be within $9 \times 10^{-6} \sim 13 \times 10^{-6}{ }^{\circ} \mathrm{C}^{-1}$ by changing its composition and its cost may be less than that of CSZ.

\section{Conclusions}

From the results of this analysis, the following points were clarified. For the 4-layered structure supported by $\mathrm{CSZ}$, the $\sigma_{z z}$ and $\sigma_{\theta \theta}$ in the electrodes are too large to prevent its deterioration. The 3-layered structure can overcome this demerit. If the total thickness of the two electrodes is more than 60 times the thickness of the electrolyte, these stresses due to the difference in CTE decrease to a magnitude of several $\mathrm{MPa}$. In this case, $\sigma_{r r}$ is a small tensile stress. Finally, the residual stress of the 4 layered type is reduced using the support tube of which CTE is larger than those of electrodes.

\section{References}

1) N. Q. Minh, J. Am. Ceram. Soc., 76, 563-88 (1993).

2) K. Kordesch and G. Simader, "Fuel Cells and Their Applications," VCH, Weinheim, New York, Basel, Cambridge, Tokyo (1996) pp. 2-21.

3) K. A. Muragesamoorthi, S. Srinivasan and A. J. Appleby, "Fuel Cell Systems," Ed. by L. J. M. J. Blomen and M. N. Mugerwa, Plenum, New York (1993) pp. 465-91.

4) K. Kanamura, S. Yoshioka and Z. Takehara, Bull. Chem. Soc. Jpn., 65, 309-13 (1992).

5) K. Kanamura and Z. Takehara, Bull. Chem. Soc. Jpn., 66, 2797-803 (1993).

6) H. Itoh, T. Yamamoto, M. Mori and T. Abe, Proc. 4th Int. Symp. SOFCs, SOFC Soc. Japan, Yokohama (1995) pp. 63948.

7) O. Yamamoto, Y. Takeda and T. Kojima, Proc. Int. Symp. SOFCs, SOFC Soc. Japan, Nagoya (1989) pp. 148-61.

8) T. Kawada, N. Sakai, H. Yokokawa, M. Dokiya and I. Anzai, Solid State Ionics, 50, 189-96 (1992).

9) H. Yokokawa, N. Sakai, T. Kawada and M. Dokiya, Solid State Ionics, 52, 43-56 (1992).

10) A. Khandkar, S. Elangovan and M. Liu, Solid State Ionics, 52, 57-68 (1992).

11) J. A. M. van Roosmalen and E. H. P. Cordfunke, Solid State Ionics, 52, 303-12 (1992).

12) H. Yokokawa, T. Horita, N. Sakai, T. Kawada, M. Dokiya, H. Nishiyama and M. Aizawa, Proc. 4th Int. Symp. SOFCs, SOFC Soc. Japan, Yokohama (1995) pp. 975-84.

13) U. B. Pal and S. C. Singhal, J. Electrochem. Soc., 137, 293741 (1990).

14) M. F. Carolan and J. N. Michaels, Solid State Ionics, 37, 18995 (1990).

15) J. P. Dekker, V. E. J. van Dieten and J. Schoonman, Solid State Ionics, 51, 143-45 (1992).

16) Y. Takeuti and N. Noda, "Netu-ouryoku," 3rd ed., Nissin Syuppan (1989) pp. 76-109.

17) J. K. MacKenzie, Proc. Phys. Soc., B63, 2-11 (1950)

18 ) P. S. Turner, J. Res. NBS, 37, 239-50 (1946).

19) A. O. Isenberg, National Fuel Cell Seminar Abstracts (1982) pp. 154-59. 